\title{
Information-applied Technology for SES on subway thermal environment simulation
}

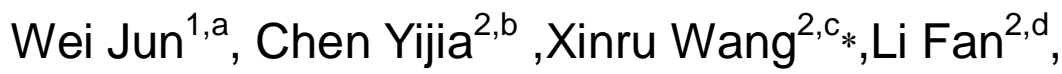 \\ Song Pan ${ }^{2, e}$, Huiyu Xue ${ }^{2, f}$, Yiyi Xiang ${ }^{2, g}$,Lang Xie ${ }^{2, h}$ \\ ${ }^{1}$ North china institute of science and technology, Beijing, China \\ ${ }^{2}$ Beijing university of technology Institute of Construction project, China \\ aweikin@ncist.edu.cn , blucjyijia@sina.com , c1070815371@qq.com,
}

Keywords: subway; SES software; simulation

Abstract: With the development of the city, the subway has been developed vigorously. along with a large number of subway construction, the use of subway design simulation software was more and more prominent. SES simulation software is commonly used software in China Subway Thermal Environment Simulation and Design, With the premise of subway operation mode determined to simulate the thermal environment of the subway, to simulate the thermal environment of the subway. This article built the simulation model of the subway stations in a realistic line in the hot summer and cold winter area, to simulate and analyze the subway tunnel ventilation, temperature, the conclusion is that the environment within the subway is reasonable and comfort.

\section{Introduction}

As the rapid development of the city, the traditional mode of transportation can't satisfy people's needs and more and more urban underground rail transit is popular. The subway is widely developed due to its large passenger capacity and convenience. At the same time, some problems such as large investment and poor running are also growing along with the development of the subway .In order to better operate and use the subway, the subway design professionals use the SES software to design and simulate the thermal environment of subway.

Many researchers with SES software have carried on the simulation analysis about subway.Zhou weijun ${ }^{[2]}$ with SES based on the certain subway line established model .In view of the platform screen door system and open system transition season ,Zhou weijun simulated the temperature distribution of metro tunnel and compared the energy consumption of two loop control

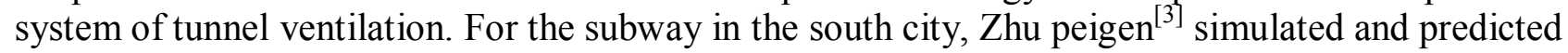
wind speed, temperature of long-term (monthly) and short-term (hourly), the changes of the station air-conditioning load and control energy consumption in different positions under different control mode. By simulating the temperature of different orbits' exhaust air using the SES, Shih - Cheng, $\mathrm{Hu}{ }^{[4]}$ obtained the minimum air volume that satisfy the tunnel design temperature. For SES software, its calculation method and principle lack of research, results of the simulation lack of accurate evaluation. The paper The bulid the model of subway in hot summer and cold winter area,simulates and analyzes ventilation and temperature of the tunnel and checks the rationality of the environment in subway tunnel.

\section{The introduction of SES software}

SES, the Subway Environment Simulation (SES) Computer Program, was first published by Petaluma Company after years of efforts with the sponsor of Volpe National Transportation Systems Center of U.S. Department of Transportation. So far, the SES program has been used to analyze around 26 subway systems distributed in five continents, including the environmental control calculation for metro line 1 and 2 in Shanghai.

The SES program provides dynamic simulations of a variety of bi-direction trains in multi-track subway system. The capabilities of the SES program permit the users to simulate the 
long-term or short-term dynamic process in different train conditions, passenger flow conditions, the structure of platforms, and the operations of the air ventilation and air conditioning in different complicated district; to ascertain the continuous value of airflows, temperature, humidity and air conditioning requirements as well as to simulate the maximum, minimum and average of airflows, temperature, humidity on tunnels, air shaft and station in any conditions, and to ensure the ventilation scheme when clog or fire accident happened in a district.

SES mainly consists of four separate and interrelated sub-program: train movement sub-program, and aerodynamic sub-program, temperature/humidity sub-program, the accumulation/environmental control sub-program. The interface is shown in figure $1 .$.

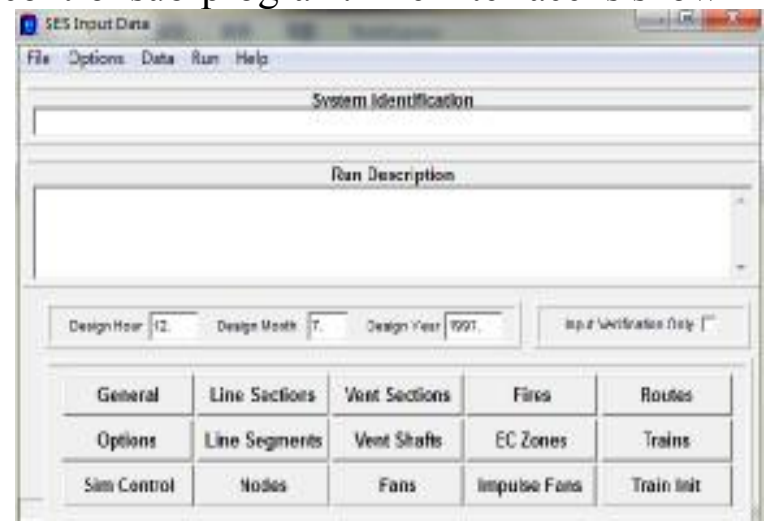

Fig. 1 .The interface of the SES

\section{The build of the model}

The model line's total length is 45.40 kilometers, including underground length of 36.55 kilometers, elevated line length of 8.85 kilometers. There are twenty-seven stations in this line across the board, including twenty-five underground stations, two elevated stations, and fourteen transfer stations, The average distance between stations is 1.721 kilometers. The object of this simulation is a project designed tenders: Station 1-- station 2-- Station 3, three stations two intervals in total.For conventional circuit, simulation consisted of three station, 10 and 11 well ventilated wind sections of the system, the result has the feasibility and validity ${ }^{[6]}$. To minimize the difference with actual model, avoid the influence of inward and outward, Reference Huazheng Bo paper ${ }^{[7]}$, On the basis of this simulation model of two intervals of three stations on each sides agreed to add three structural forms of the station and four intervals, a total of nine stations 10 tunnel as a research model. Add six station named: left 1, left 2, left 3, right 1 , right 2 and right 3 . The station 1 to 3 was denied as downlink (right line), contrary to the upline (left line). Nine stations are underground island stations, stations on the effective length of 140 meters, all sections of the construction method are drilling and blasting. Forward evening during the summer peak, the number of trains running on 30 pairs per hour, opened the exhaust hot air,SES simulated at the most unfavorable conditions, the simulation longed for 3600s, draw network diagram in Figure 2 .

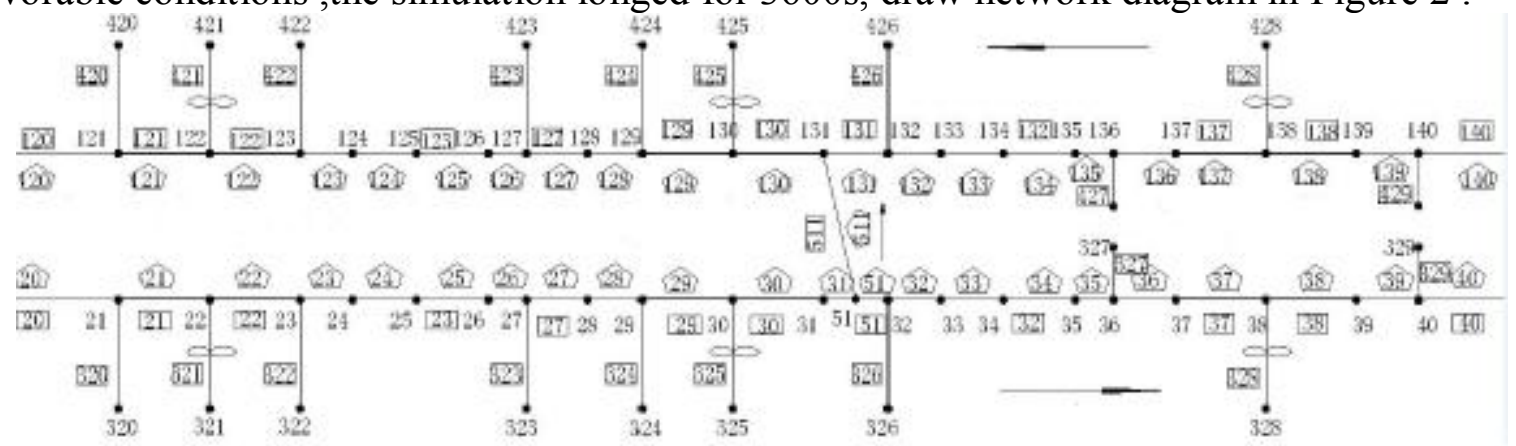

Fig.2 . SES4.1 station network node (1-2-3) 


\section{The analysis of the simulation results}

According to the detailed design information offered from design institute about a line in the hot summer and cold winter area, the determinate important parameters of modeling are as follows:

(1)This simulation choose long-term summer evening peak times 17:00-18:00 simulation, at this point when there are 30 pairs of trains per hour, which means the interval between each train is 120s;

(2) Opening the piston at both ends of the air duct and the heat removal fan when modeling, the rated air volume of the heat removal fan is $40 \mathrm{~m}^{3} / \mathrm{s}$, and the rated wind pressure is $800 \mathrm{pa}$.

The result of the modeling is shown in figure3. The positive number represents the value of upline of each nodal point in the figure, and the negative number means the value of downline.

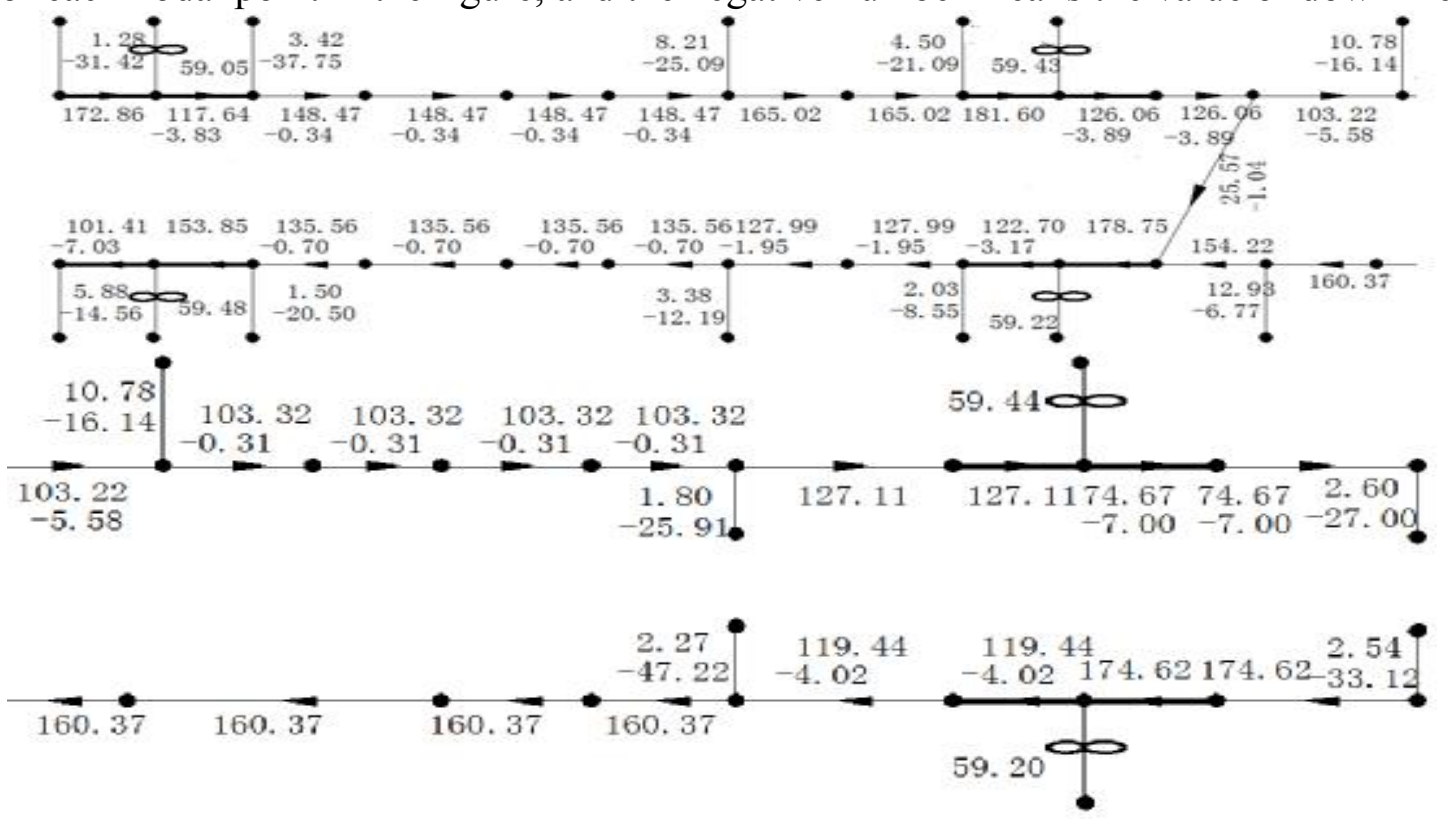

Fig.3 . SES4.1 ventilation result of tunnel

What is shown in figure 4 is the hour average of the air volume in vent shaft of the tunnel. Combining with the figure 3 , we can find that the change of the air volume of 3 vent shafts in each station will form the shape like " $\wedge$ ", and the air volume of the vent shaft in the station entrance is more than the station end. It also shows that because of the same geometric parameter of the piston ventilation shaft and the heat removal shaft, the exhaust air volume of the heat removal shaft is almost equal, stabilizing at $57 \mathrm{~m}^{3} / \mathrm{s}$ (every vertex in the figure) with the constant number and interval of the trains, the same way of ventilation and the same stoppage time. On account of one-way working condition of the exhaust fan, there is no reverse flow. The average of the exhaust air volume of the heat removal shaft in the 9 stations in the SES program is $56.80 \mathrm{~m}^{3} / \mathrm{s}$, which means the quantity of ventilation of the vent shaft is consistent with the design standard of the heat removal fan, so the ventilation is appropriate.

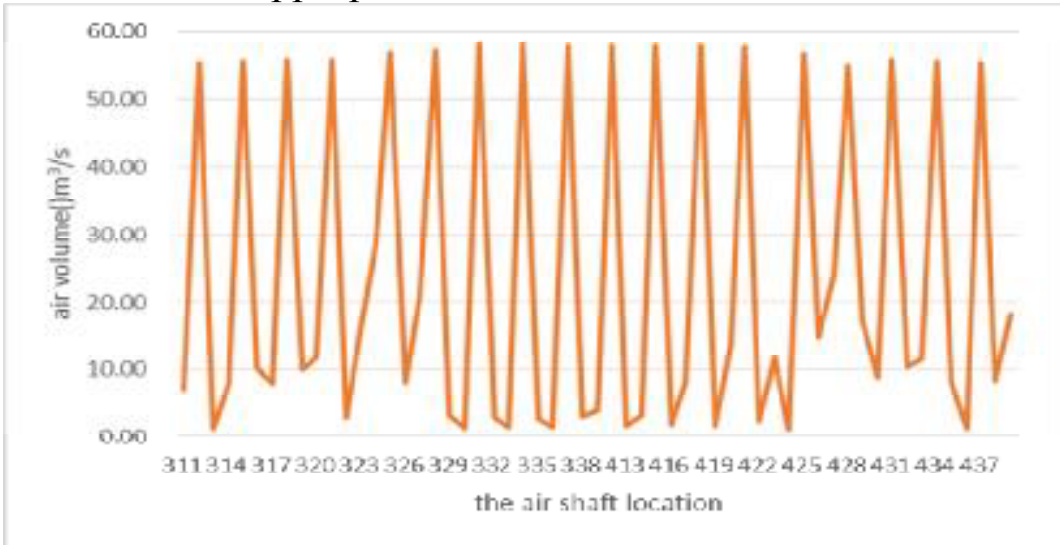

Fig.4 . SES4.1 average air volume in air shaft 


\section{Conclusion}

The paper comes to the following conclusions by using SES software to simulate and study the subway in the hot summer and cold winter area.

1 In the simulation, it is necessary to consider and try to eliminate the influence of external environment on the simulation object. To minimize the difference with actual model and avoid the influence of inward and outward, three stations was added on the basis of the three stands and two interval model, the simulation that their structure is consistent of four interval on each side. There are a total of nine stations with ten tunnels as the research model.

2. In the hot summer and cold winter area, the effect of the ventilation is good in the subway. The exhaust air of row of hot blast hole is steady at $57 \mathrm{~m}^{3} / \mathrm{s}$. Ventilation rate of wind well is in compliance with the design standard of heat exhaust fan and the ventilation is reasonable in the subway.

\section{References:}

[1]New progress of subway ventilation and air conditioning system energy saving. [2]Weijun Zhou, Lian Feng, Shihui Luo, The transition season subway environmental control model comparison and analysis, Refrigeration and air conditioning (Si Chuan). 2008, (03): 101-103. [3]Peigen Zhu,Yinxin Zhu,Xiaofeng Li, Schemes and analysis of subway ventilation and thermal simulation,Fluid machinery. 2004, (11): 39-42.

[4]S. C. Hu and J. H. Lee. Influence of Platform Screen Doors On Energy Consumption of the Environment Control System of a Mass Rapid Transit System: Case Study of the Taipei MRT System. ENERGY CONVERSION AND MANAGEMENT. 2004, 45(5): 639-650.

[5]Jinli Zheng, Weijie Hu, Main simulation results and analysis of the Shenzhen subway project environment control, Underground engineering and tunnel ,2000,1:37-48.

[6]Zhengbo Hua ,Platform screen door system of metro rail line area ventilation mode research ,Master degree theses of master of southwest jiaotong university, school of mechanical engineering 